\title{
Selecting early-career researchers: the influence of discourses of internationalisation and excellence on formal and applied selection criteria in academia
}

\author{
Channah Herschberg ${ }^{1}$ • Yvonne Benschop ${ }^{1}$ • \\ Marieke van den Brink ${ }^{2}$
}

Published online: 17 February 2018

(C) The Author(s) 2018. This article is an open access publication

\begin{abstract}
This article examines how macro-discourses of internationalisation and excellence shape formal and applied selection criteria for early-career researcher positions at the mesoorganisational and micro-individual levels, demonstrating how tensions between the various levels produce inequalities in staff evaluation. In this way, this article contributes to the literature on academic staff evaluation by showing that Selection Committee members do not operate in a vacuum, and that their actions are inextricably linked to the meso- and macrocontext. This study draws on qualitative multi-level data that comprise institutional-level policies, recruitment and staff protocols, job postings and individual-level interviews and focus groups with Selection Committee members. Findings show that a majority of Selection Committee members consent to university policies and macro-discourses when evaluating early-career researchers, but a smaller group questions and resists these criteria. Furthermore, the analysis revealed four inequalities that emerge in the application of criteria and reflect on disciplinary differences between the Natural and Social Sciences. The article concludes that with only a few Committee members to critically question and resist formal selection criteria, they limit the pool of acceptable candidates to those who fit the narrow definition of the internationally mobile and excellent early-career researcher, which may exclude talented scholars.
\end{abstract}

Keywords Early-career researchers $\cdot$ Recruitment and selection criteria $\cdot$ Neoliberalism · Excellence $\cdot$ Internationalisation $\cdot$ Inequalities

Channah Herschberg

c.herschberg@fm.ru.nl

1 Institute for Management Research, Radboud University, P.O. Box 9108, 6525 AJ Nijmegen, the Netherlands

2 Radboud Social Cultural Research, Radboud University, P.O. Box 9104, 6500 HE Nijmegen, the Netherlands 


\section{Introduction}

This article contributes to the literature on academic staff evaluation, especially to debates concerning recruitment and selection criteria. Scholars in this field perceive attraction and retention of talented personnel as a challenge for universities (Musselin 2010; Thunnissen et al. 2013). They present a (critical) evaluation of scientific quality and individual merit that (re)produce inequalities, for example in pre-selection processes for academic positions (Nielsen 2016) and in the construction of academic excellence (Van den Brink and Benschop 2012). Although these studies have delivered valuable insights into the production of inequality in academic evaluation, emphasising the role of individual evaluators, they often neglect how these evaluators are influenced by macro-discourses in the context of the global, neoliberal university. It is argued that evaluators do not operate in a vacuum, and that their actions are inextricably linked to meso-level evaluation policies within their organisations and the macro-discourses of internationalisation and excellence. Higher-education institutions increasingly engage in international competition with each other for academic staff. As the academic labour market has become global (Slaughter and Leslie 1997), international mobility is more and more perceived as a crucial element of an academic career (Jepsen et al. 2014). Additionally, excellence seems to increase in importance as a criterion in staff selection decisions, gauged as a neutral and objective, merit-based measurement of productivity (Van den Brink and Benschop 2012).

The aim of this study is to examine how macro-discourses of internationalisation and excellence shape formal and applied selection criteria for early-career researcher positions at the meso-organisational and micro-individual levels, demonstrating how tensions between the various levels produce inequalities in staff evaluation. The research question is how are academic selection criteria constructed at the meso- and micro-level in the context of macrodiscourses of internationalisation and excellence? In this study, the focus is on selection criteria for early-career researchers, as in this phase, it is decided who are included or excluded from academic careers. The findings show that this is a particularly challenging task for evaluators, as the assessment of early-career researchers, and Tenure-Track Assistant Professors in particular, is based on potential, instead of the long track record of performance of senior researchers. The findings are based on two case studies of a Natural Sciences and a Social Sciences Department of a university in the Netherlands. A qualitative content analysis was conducted, analysing university policies, recruitment and staff protocols, job postings and interviews and focus groups with Selection Committee members. The multi-level analysis has shown tensions between the articulations of the discourses of internationalisation and excellence at multiple levels and has identified four inequalities that are produced in the application of selection criteria.

\section{Evaluating academic staff in the neoliberal university}

Since mid-1980, Western higher education institutions have become subject to the growing role of market forces and commercial values (Washburn 2005), resulting in the corporatisation and neoliberalisation of academia (Gill 2009; Olssen and Peters 2005). This transition has been fuelled by the growing hesitance of Western governments to spend public money on public services (De Boer et al. 2007), which has led to decreasing direct investments in higher education among other effects. Furthermore, higher-education institutions are increasingly 
evaluated on their output, such as number and quality of publications and number of graduated students (De Boer et al. 2007; Teelken 2012), which creates pressure to continuously raise these numbers. New forms of assessing academic performance or scientific excellence come with this development.

The changing academic landscape has led to an increase in studies on staff evaluation, and specifically, the evaluation criteria (Lamont 2009; Musselin 2010; Van Arensbergen et al. 2014). Science studies have predominantly engaged with the accuracy of contemporary performance indicators, such as productivity, citation indexes and peer review (e.g., Anninos 2014; Basu 2006; Werner 2015). Human Resource Management-oriented research has examined the HR practices facilitating the recruitment, selection and retention of academics and has recently centred on talent management (Davies and Davies 2010; Thunnissen et al. 2013). Research in sociology and (critical) organisational studies have emphasised the social construction of evaluation criteria (Lamont 2009), group dynamics during the evaluation process (Van Arensbergen et al. 2014) and the production of inequalities in the process and criteria (Nielsen 2016; Özbilgin 2009; Van den Brink and Benschop 2012; Lund 2015).

This article adds and builds on this latter category of studies by examining how evaluators construct and apply evaluation criteria in academic selection procedures. These criteria are not constructed and applied in a vacuum but are embedded in academic, national and global contexts. In the wake of the neoliberalisation of academia, the academic labour market is globalised (Slaughter and Leslie 1997); however, multiple studies have shown how academic labour markets are still distinguished by substantial national characteristics (Enders and Teichler 1997; Musselin 2005, 2010). In her extensive study on hiring processes, Musselin (2010) describes how national career systems, as well as institutional and disciplinary features, impact both the ideal type of candidate and selection criteria. This study builds on Musselin's approach by including macro-discourses when studying selection criteria, which has not been done before.

At the macro-discursive level, two grand discourses that seem most prominent in the current debate on the neoliberal and global university are taken into account: the discourse of internationalisation (e.g., Leisyte and Rose 2016; Fabricius et al. 2017; Schartner and Cho 2017), and the discourse of excellence (e.g., Butler and Spoelstra 2014; Ramirez and Tiplic 2014; Van den Brink and Benschop 2012). Internationalisation has increasingly become a keyword in policies of European higher-education institutions (Fabricius et al. 2017), as a process of integrating an international dimension into university research, teaching and service functions (Knight 1994). Excellence has also become a 'holy grail', a norm or standard that all higher-education institutions should supposedly strive for. Ramirez and Tiplic (2014) found a discursive shift in European higher education research publications from a focus on student access to higher education to an emphasis on management, performance and excellence. The pursuit of excellence influences both university governance and the daily practices of researchers (Butler and Spoelstra 2014).

This study uncovers how global discourses are translated into local contexts, by studying the dynamic interaction between macro-discourses, formal organisational policies and actual practice in staff selection and focus on how Selection Committee members take the context into account in their application of selection criteria. In line with Pringle and Ryan (2015), and Panayiotou et al. (2017), it is argued that studying the interplay between macro-, meso- and micro-levels can demonstrate discrepancies and tensions between the various levels. Insight into these tensions allows for a better understanding of the complex field, in which academic evaluators manoeuvre and how inequalities are produced. 
Of relevance to this research are previous studies that theorise how individuals respond to the neoliberalisation of the academy (Anderson 2008; Field 2015; Teelken 2012). These studies reveal a complex picture of individual responses, which show how people are not passive recipients and take a stance when confronted with institutional pressures. This study has distinguished between consent as the active adherence and participation in enforcement of rules (Burawoy 1979), compliance as the acquiescence to rules and resistance as taking an active stance against the rules (Ashcraft 2005; Kärreman and Alvesson 2009). This distinction between consent, compliance and resistance informs the analysis of Selection Committee members' various responses to macro-discourses and university policies.

\section{Methodology}

\section{Research design}

The research question requires a case-study approach, as this allows for a detailed study of a particular context (Bryman 1989), and provides an opportunity for generating theoretical insights, as a result of contrasting findings (Bryman and Bell 2007). Case studies help to achieve the research aim to gain a contextual understanding of the effect of macro-discourses of internationalisation and excellence on recruitment and selection criteria for Tenure-Track Assistant Professorships in two departments of a university in the Netherlands. The Assistant Professorship tenure-track central in this study typically starts with a temporary appointment, to become a permanent Assistant or Associate Professor appointment upon a positive evaluation after 4/6 years (De Goede et al. 2013). A comparative perspective between research departments within the Natural and Social Sciences disciplines has been chosen, because disciplines vary considerably with regard to the evaluation of knowledge development contributions (Lovitts 2007), the compositions of students and staff, career patterns and recruitment and selection criteria and practices (Van den Brink et al. 2013).

\section{Data collection}

The prevalence of macro-discourses of internationalisation and excellence are well-articulated in the literature on the neoliberal university. It will be studied how these discourses are translated to the meso- and micro-level. At the meso-organisational level, both the broader university level and the specifics of a Natural Sciences and a Social Sciences Department are considered. University policy documents have been collected, as well as recruitment and staff protocols and job postings of the two departments to study formal selection criteria. These textual data provide an overall picture on how an institution accounts for its activities (Silverman 2011). The university policies included a strategic plan (2015), internationalisation policy (2013) and language policy (2014) of the university. In addition, a recruitment protocol (n.d.) and a tenure-track memorandum (2010) for Assistant Professorship positions of the Natural Sciences Department were collected. For the Social Sciences Department, a staff development plan (2013) was included. Finally, 23 job postings for Tenure-Track Assistant Professorships (18 from the Social Sciences and 5 from the Natural Sciences) were analysed, covering all published job postings for Tenure-Track Assistant Professorship positions in the period 2010-2014. 
At the micro-individual level, nine semi-structured interviews with Selection Committee members (hereafter Committee Members) were conducted. Also, focus groups with Committee Members were conducted: one in the Natural Sciences with four respondents and one in the Social Sciences Department with three respondents (see Table 1 for more information on the respondents). This study makes use of focus groups, because this enabled respondents to construct criteria in interaction with each other and to discuss, negotiate and question the criteria proposed (Bryman and Bell 2007). The respondents for both the interviews and the focus groups were selected from those that took part in Selection Committees for Tenure-Track Assistant Professorship positions in the period 2010-2014. Their names were retrieved from appointment reports. During the interviews and focus groups, respondents constructed the criteria that they consider important in the recruitment and selection of Tenure-Track Assistant Professors. ${ }^{1}$ They were structured around two themes: selection criteria for Assistant Professorship positions and department policies regarding recruitment and selection. The interviews lasted between 1 and $2 \mathrm{~h}$, and the focus groups lasted $2 \mathrm{~h}$. The interviews and focus groups were recorded with respondents' permission and transcribed verbatim.

\section{Data analysis}

In the meso-level data (university policy documents, department protocols and job vacancies), the analysis started with searching for textual signposts connected to internationalisation and excellence. This exercise helped selecting relevant excerpts related to the macro-discourses. Then, these excerpts were open-coded to analyse which specific aspects were related to internationalisation and excellence. Then, a second round of coding was carried out, focused on recruitment and selection criteria for Assistant Professors. This resulted in codes, such as talent, quality, promise, excellence, teaching abilities, number and quality of publications, English language capabilities, Dutch language capabilities, mobility, international recruitment and selection criterion. A comparison of the Natural Sciences Department with the Social Sciences Department was made in order to find similarities and differences.

Subsequently, it was analysed how the meso-level criteria were constructed at the microlevel. To analyse both the interview transcripts and focus group transcripts, qualitative content analysis (Lieblich et al. 1998) was conducted. Codes derived from the analysis of the mesolevel criteria were used, but an open stance to other findings on selection criteria related to internationalisation and excellence was ensured. Due to the richness of interview and focus group data, the analysis resulted in very specific additional codes in this step, such as visits abroad, nationality, foreign countries, subjectivity, potential, independence and international network. Then, the criteria found on the meso-level (university and department) were compared with the micro-level (Committee Members). This comparison between meso- and microlevel was made for both the Natural Sciences Department and the Social Sciences Department. Next, Committee Members' accounts of their application of criteria were explored. Their responses were analysed as instances of consent, compliance and resistance to selection criteria stemming from meso-level university and department policies and macro-discourses of internationalisation and excellence. The multi-level analysis also enabled us to identify four inequalities in the application of criteria.

\footnotetext{
${ }^{1}$ This article is limited to the construction of criteria by Committee Members and does not unravel the two-stage selection process of applying criteria to actual candidates (in CV assessment and job interviews).
} 
Table 1 Interview- and focus group respondents per department

\begin{tabular}{llll}
\hline Department & Respondent & Sex & Position \\
\hline Natural Sciences & Interview respondent 1 & Male & Associate Professor \\
& Interview respondent 2 & Male & Professor \\
& Interview respondent 3 & Male & Professor \\
& Interview respondent 4 & Male & Professor \\
& Interview respondent 5 & Male & Professor \\
& Focus group respondent A & Male & Professor \\
& Focus group respondent B & Male & Professor \\
& Focus group respondent C & Male & Associate Professor \\
& Focus group respondent D & Male & Professor \\
Social Sciences & Interview respondent 1 & Female & Assistant Professor \\
& Interview respondent 2 & Female & Professor \\
& Interview respondent 3 & Male & Professor \\
& Interview respondent 4 & Male & Professor \\
& Focus group respondent A & Female & Professor \\
& Focus group respondent B & Male & Associate Professor \\
& Focus group respondent C & Female & Associate Professor \\
\hline
\end{tabular}

\section{Results}

First was explored if and how the prevailing macro-discourses of internationalisation and excellence, as articulated in the literature, were adopted at the meso-university level, followed by the meso-departmental level. At the departmental level, a distinction was made between the Natural and Social Sciences. Then, it was explored if and how Committee Members apply the macro- and meso-level criteria when selecting Tenure-Track Assistant Professors. The results illustrate how the translation from the macro- and meso-level to the micro-level creates inequalities for early-career researchers in the selection process.

\section{University policies}

In this section, it is shown how the macro-discourses of internationalisation and excellence have spilled-over to the meso-university level.

The main objective of [the university's] internationalisation policy is to contribute to enhancing the quality of its core activities: research, education and service. (Internationalisation policy, 2013, p. 1)

Achieving the proposed targets [of the internationalisation policy] will contribute to enhancing the quality of [the university] and, as a result, its international reputation. (Internationalisation policy, 2013, p. 9)

The most interesting finding in the university policies is the interconnectedness of internationalisation and excellence. In these quotes, taken from the internationalisation policy, can be seen how discourses of internationalisation and quality are intertwined. The quotes suggest a self-reinforcing cycle, in which more internationalisation will enhance quality related to research, education and service, which in turn, will lead to an enhanced international reputation. The policy reveals that the achieved international reputation should, as a result, increase acquisition of research funds and top researchers, which will further enhance the university's reputation, and spiral upward to even more 
funds and more top researchers, and so on. The policy document of the case-study university presents the relation between internationalisation and quality as self-evident, as it does not explicate how internationalisation results in quality enhancement. Previous studies couple internationalisation to a shortage of academic staff due to the 'massification' of higher education (e.g. Richardson 2009; Richardson and Zikic 2007). The only link between internationalisation and excellence found in the literature is from Fabricius et al. (2017), who argued that transnational student mobility increases the quality of education. The present analysis of university policies has shown the connection between internationalisation and excellence is taken for granted, and, therefore, there seems to be no reason why the university should refrain from developing internationalisation policies.

The adaptation of the discourse of internationalisation at university level affects academic staff recruitment and selection in three ways. Firstly, the university aims to recruit more international staff to reach a proportion of at least $25 \%$ of all scientific staff in 2020 (Strategic plan, 2015). Secondly, the university proposes to 'explicitly include' 'foreign experience' as a selection criterion in recruitment of scientific staff (Internationalisation policy, 2013). This implies that staff coming from abroad and staff with foreign experience have better credentials than staff members who lack this experience. In the policy, it is not explained if foreign experience means international work experience or if collaboration with foreign colleagues suffices. Thus, at university level, this criterion remains rather broad, which leaves space for disciplinary and individual interpretations. Thirdly, staff members are expected to master the dominant academic lingua franca English, as it is recommended in the policy for English proficiency to become 'part of the application procedure' (Language policy, 2014, p. 3), yet, how to do so remains unclear. This is a widespread phenomenon, because also in Nordic higher education, the use of English has been strongly encouraged (Airey et al. 2017). This might not be surprising considering that English is the language of internationalisation (Fabricius et al. 2017).

When focusing on the discourse of excellence, it is found that it has been adopted in policies at university level, reflected by words, such as 'excellent', 'high-quality', 'world class', 'top' and 'prestige', yet, it did not result in a specific policy with excellence as the main topic. The document analysis shows that excellence and quality are related to research, education, staff and students, research facilities and support services (e.g. Human Resources, ICT). Excellence, thus, is a multi-purpose adjective or an empty signifier that can be applied to almost everything (Schinkel 2017). However, this study finds that the discourse of excellence is only rarely presented in university policies with reference to recruitment and selection of academic staff. Recruiting 'new talent' is the language used but 'talent' remains unspecified and is not translated into selection criteria. This makes excellence a 'fuzzy' concept that leaves room for Committee Members to select candidates based upon their interpretations of the concept.

The findings show that the university incorporates the discourses available in the global academic governmentality regime (Maesse 2017). This study finds that the university-level criteria related to both internationalisation and excellence are characterised by 'interpretative viability': 'a certain degree of conceptual ambiguity' (Benders and Van Veen 2001, p. 37). This is often the case with management discourses, as this leaves room for multiple interpretations, and facilitates organisations to broadly disseminate them (Benders and Van Veen 2001). Yet, this opens the way for inequality. 


\section{Departmental selection criteria}

\section{Internationalisation}

Within the Natural Sciences Department, the discourse of internationalisation shaped formal selection criteria for Tenure-Track Assistant Professor positions. A criterion related to foreign experience is formulated as 'some years of postdoc experience, also abroad' (Recruitment protocol, n.d., p. 3). This is in accordance with the university's goal to include foreign experience as a selection criterion, yet, at department level, the criterion is made more specific as it refers to the postdoc period, in which the experience should be acquired. Not all job postings adopt the explicit 'international' part of this criterion, despite this being documented in the recruitment protocol. As the criterion leaves 'abroad' unspecified, there still remains room for Committee Members to decide whether or not applicants' experience gained abroad is sufficient.

Also in line with university policy, the recruitment protocol and all but one of the job postings in the Natural Sciences Department request good proficiency in English. Two job postings state that this is a criterion, because Assistant Professors are supposed to teach in English. This is similar in Nordic higher education, in which English language instruction has become commonplace (Airey et al. 2017), as Anglophone is considered the norm in higher education and non-Anglophone languages, different or peripheral (Meriläinen et al. 2008). However, the recruitment protocol and job postings reveal that applicants are also requested to master the Dutch language, or do so within 2 years into the tenure-track. Job postings illustrate that this is a requirement, because Assistant Professors are expected to (also) teach in the Dutch study programme. Thus, the department requires internationalisation of staff; however, all tenure-track staff should invest in learning the local language, even though they have no guarantee that they will get tenured by the institution in the long-run. Being able to speak the academic lingua franca English is apparently not sufficient for Tenure-Track Assistant Professors. Here, the analysis illustrates how language policies are adjusted to disciplinary needs, which corroborates the finding of Airey et al. (2017), who have shown that the needs of a discipline weigh more heavily than university language policy.

In the Social Sciences Department, the discourse of internationalisation is less prominent in job postings for Assistant Professors. In contrast to the Natural Sciences Department, international work experience is not documented as a formal selection criterion. The macro-discourse and university policy have not (yet) trickled down to the formal level of the Social Sciences Department. This seems to support Richardson's (2009) findings that the value attached to international mobility differs per discipline. Indeed, she contends that researchers in the Natural Sciences (and Medical Sciences): 'were more likely to see academia as an essentially “international” profession than their counterparts in the arts and humanities' (p. S164). A small number of job postings in the Social Sciences Department request a good command of English but do not explain why this is required.

\section{Excellence}

The results show that excellence encompasses multiple academic activities and skills. In the Natural Sciences Department, excellence is related to communication skills, teaching and research and reflected by words, such as 'outstanding didactical skills'. In the Social Sciences Department, excellence — or quality — is related to research and teaching and described, for 
example, as 'record of excellence'. Similar to university policies, excellence is used as a multipurpose adjective here too. In both departments, the criteria remain unspecified and, thus, the interpretative viability of excellence remains prominent at the meso-departmental level. This is in line with Chism (2006), who also shows that excellence is undefined in teaching excellence criteria. This leaves room for interpretation for Committee Members but also makes it difficult for applicants to decide whether or not they meet the criteria.

\section{Application of selection criteria by committee members}

In this section, it is illustrated how the macro-discourses and meso-level criteria cascade to the micro-level of Committee Members who have been involved in selection procedures for Tenure-Track Assistant Professor positions in the two departments. It is shown how they consent, comply with, or resist the criteria shaped by discourses of internationalisation and excellence. Also, it is shown how inequalities are produced in the application of selection criteria.

\section{Internationalisation}

Natural sciences Most interview respondents in the Natural Sciences Department uphold the macro-discourse of internationalisation and its relation to quality. When Committee Members speak about the criteria they apply in the selection of Tenure-Track Assistant Professors, most of them argue international postdoc experience is a decisive criterion for them. The analysis shows that most respondents consent with the formal criteria documented by the university and the department; however, one focus group respondent challenged the criterion.

Respondent A: Indeed, you look at what a person has done before, mainly as a postdoc. A couple of years of postdoc experience. And we have a very international field. [...] So, you also look at international experience. You do not want someone who, let's say, got stuck in one place for the entire period from bachelor, master, $\mathrm{PhD}$ and then postdoc. Yes, you just learn more when you work in different places, in our field.

Respondent D: And a foreign country is essential?

Respondent A: Yes. [...]

Respondent D: It is almost not possible to only in the Netherlands?

Respondent A: It is strongly discouraged. I've actually done it [staying in the Netherlands after my PhD] myself. (Natural Sciences, focus group)

The quote reveals the main argument expressed by most Committee Members in support of postdoc experience abroad: 'You just learn more when you work in different places,' (which refers here to different countries). In the quote, respondent D questions if: 'a foreign country is essential' in acquiring postdoc experience. Yet, respondent A legitimises the requirement by emphasising the 'international field', in which they operate. The interview data confirm that, overall, experience acquired in an institution abroad is considered superior to experience obtained in the home country. Most respondents took the criterion of international postdoc experience for granted and did not question its relevance, thus consenting with macro- and meso-level criteria.

The analysis shows that the criterion of international postdoc experience demands mobility across country borders, which assumes that candidates are physically, psychologically, socially and financially able to travel. This requirement can be exclusionary to early-career researchers 
who face restrictions to their international mobility and, thus, create inequality among candidates. Furthermore, the excerpt from the focus group reveals intergenerational inequality (Özbilgin 2009) inherent in the selection process for Assistant Professors, showing that Committee Members hold applicants to standards that they 'would not have met had they been held to them when they were junior scholars' (Özbilgin 2009, p. 115). This implies that selection criteria have become increasingly demanding for early-career researchers.

Focus group respondents briefly discussed alternative forms of gaining international experience besides a postdoc abroad, such as short-term research visits, conference visits and international project cooperation. However, respondent D argued that the Institute's Director and Faculty Board do not value such alternatives. The respondent illustrated that the organisational culture, nourished by the Dean and the Director, imposes the criterion of international postdoc experience upon Assistant Professors. Not meeting this criterion has a derogatory connotation of being 'provincial' (i.e. narrow-minded), which also implies lower quality. Respondent D expressed that he has difficulty with this connotation, as he thinks someone in his field without international work experience can be a good scientist. In contradiction to his colleagues, and to the findings at meso-level, he decouples internationalisation and quality. However, the respondent argued that Committee Members anticipate disapproval of the Dean when nominating a candidate without international postdoc experience and, therefore, he complies with the departmental selection criterion. This is one of the few examples of compliance.

Further, the data reveal that some Committee Members restrict what counts as international experience. These Committee Members argued that international experience per se is not sufficient: they only favour work experience in certain universities and countries and not others. A focus group respondent argued that not all universities in a foreign country are considered good places to work. Here, the findings show how Committee Members work with the room for interpretation created by meso-level criteria. The data revealed that Committee Members value work experience in the USA most because the 'system', 'culture' and 'way of working' are considered entirely different there. Respondents also mentioned England and Germany as countries to yield valuable work experience. Thus, the practice here is not if internationalisation plays a role in recruitment and selection but what type of internationalisation. This study shows that this results in the exclusion of applicants who obtained postdoc experience in less prestigious institutes or peripheral countries. This creates inequalities among early-career researchers based on Committee Member's preference for 'leading' institutions. This exclusionary practice only surfaces when the formal criterion that hints at a universal idea of international experience is confronted with the narrow criterion applied by Committee Members. Also, it shows how internationalisation and excellence are intertwined when excellence is dependent on only a selection of valued countries and universities.

In contrast to formal policies, English and Dutch language proficiency were not mentioned as important criteria in the selection of Assistant Professors. One interview respondent referred to the criterion of Dutch language proficiency as one of the formal criteria to get tenure. None of the Committee Members made a reference to English language proficiency, implying this is taken for granted in selection procedures, possibly because Committee Members assume that all applicants are fluent in English due to the perceived international character of their field.

Social sciences A number of years as a postdoc in an international setting - as is required within the Natural Sciences Department-seems no prerequisite in the Social Sciences 
Department. Most likely, this is due to the fact that in the Natural Sciences, the postdoc position is a necessary step on the academic career ladder, whereas in the Social Sciences, this is more rare (Bessudnov et al. 2015). The analysis reveals that interview respondents considered international experience a non-decisive criterion in the selection of Tenure-Track Assistant Professors. For them, international work experience is more an additional benefit than a necessity. Thus, they consent with department policy; however, it shows a discrepancy with university policy that prescribes foreign experience as a selection criterion.

In the focus group, one respondent made the criterion of international experience salient, after which, she negotiated the criterion with another respondent.

Respondent A: What I mean with experience abroad are not so much foreigners. [...] I mean I think it is quite important — and that has to do with the independence that I just mentioned-like having been at another university for a couple of months. That you go and do that, curiosity, that you are willing to take such steps. But also abroad in the sense of conference visits, that you show on your $\mathrm{CV}$ or in the interview that you visit conferences, that you present papers, that you are working on a network. And why? Because you just know that it is important for someone's career. This is particularly important at the beginning of a candidate's career. So when candidates show that they are working on this, I think it is a positive criterion.

Respondent C: And it shows that the candidate knows the rules of the game.

Respondent A: Yes. [...]

Respondent C: Do you have fear of flying? If the answer is yes, well, that is a problem. (Social Sciences, focus group)

For respondents $\mathrm{A}$ and $\mathrm{C}$, international experience is something that is needed for building an academic career, 'particularly' 'at the beginning', which can be gained via different routes: research stays at universities abroad and conference visits, i.e., long- and short-term international experience. They do not fully consent with the selection criteria formulated by the department. During the focus group discussion, international experience became a signifier for 'independence', 'curiosity' and 'willingness'. By doing so, Committee Members link international experience to personal qualities. Additionally, they argue that going abroad demonstrates devotion and suitability. Respondent $\mathrm{C}$ briefly touches upon a problematic aspect of this criterion: 'fear of flying'. She describes this as a legitimate explanation to not operate internationally, but at the same time, she presents it as 'a problem' if this would arise during a selection process. Later in the conversation, the focus group respondents argued that conference visits require financial means, so that a lack of finances can hamper the opportunity to gain international experience. Respondent $\mathrm{C}$ illustrated that even though they consider international experience 'particularly important' a lack of such experience is not a reason to reject an applicant given that the 'rest of the CV looks good'. Reinforcing the importance of this criterion, the respondent stated that an applicant who does not meet this criterion has 'something to compensate for'. Similar to the findings in the Natural Sciences Department, by applying the requirement of international work experience, Committee Members exclude candidates who face physical, psychological, social or financial restrictions to their international mobility. The results show that structural hindrances to mobility are hardly recognised by Committee Members and if they do acknowledge them, the responsibility to deal with these hindrances is placed with the candidate.

In contrast to university policies, interview and focus group respondents revealed some reservations towards hiring foreign applicants, showing resistance towards university policy. 
The main reservations regarded English and Dutch language proficiency. Focus group respondents questioned the fit of foreign applicants in the department and doubted if the level of English in application letters corresponds with applicants' spoken English. The data show that they make assumptions about candidates' level of English, which can put candidates of certain nationalities at more of a disadvantage than others, leading to potential inequality regarding nationality.

An interview respondent addressed an issue encountered with a foreign applicant regarding her command of Dutch:

Moreover, this was someone from abroad who was teaching in Dutch and that is something that students cannot always deal with. Having an accent and the fact that you lose some finesse in another language than your mother tongue, to students is a sign that it is not good. (Social sciences 1)

This Committee Member explains that Dutch-speaking foreign candidates can have a disadvantage, because Dutch students tend to evaluate them less favourably than native Dutch speakers. In the case illustrated by the respondent, these low evaluations hampered the candidate's job application. In practice, teaching in the local language (Dutch) is constructed as problematic for both foreign Assistant Professors and (local) students. The dimension of spoken language is not recognised by Chism (2006) as a factor leading to teaching excellence, yet this study shows that Committee Members take this into account when making selection decisions. The data have revealed that despite the university's aim to increase the percentage of foreign staff, Committee Members perceive risks in hiring foreign applicants. This illustrates how foreign applicants can be excluded from the selection process, an inequality that surfaces at the micro-level. Unlike the findings at the meso-university level, the results at the microlevel show that internationalisation and excellence are not necessarily always intertwined.

\section{Excellence}

Natural sciences The Committee Members in the Natural Sciences Department did not refer to excellence, as the university and department policies do, but they used the rhetoric of quality. This study finds that research quality is considered the most decisive criterion in the selection of Assistant Professors. However, when respondents were asked to explain how quality is measured, the data show that this is a complex endeavour:

Respondent: That [quality] is hard to objectify, because you cannot put it in numbers. [...] It is subjective; it also has to do with interest. I consider one topic more interesting than the other. Some people conduct a specific research, because they think it is interesting, but I might not share their interests. Thus, I would put this candidate lower [in ranking] than someone whose research I find exciting.

Interviewer: [...] How do you measure the quality of publications?

Respondent: [...] Actually, you just have to read those publications, of course. As nobody has time to do so, this happens too rarely. (Natural Sciences 4)

The respondent argues that his personal interest in and excitement about research topics play a role in evaluations. Additionally, he explains that in order to judge the quality of applicants' publications, one should read them but this 'happens too rarely' because 'nobody has time to do so'. The subjective and hasty evaluation of quality makes it an ambiguous undertaking, which creates room for personal preference and bias. This honest reflection on the 
subjectivity of evaluation runs contrary to the opinion of most grant reviewers in the study of Porter (2005), who rate the review panel's objectivity as very high.

Even though Committee Members want to select on scientific quality, they argue that this is particularly difficult for Assistant Professorships, as applicants for such positions are still early in their career. A respondent argued that because of the junior level of applicants, Committee Members cannot judge the quality of publications on its impact. Therefore, he explained to look for other signifiers of quality, such as 'the length of publications', 'celebrity' co-authors, the esteem of journals, but also what publications are still to come ('pre-prints' and papers 'in the pipeline') (Natural Sciences 3). Thus, the 'publishability' or publishable quality of the work is assessed (Clarke and Lunt 2014). Hence, the university's and department's strive for excellence becomes difficult to apply as a selection criterion, particularly for early-career researchers, who have limited evidence to prove their scientific excellence. This implies that the measurement of excellence is particularly suited for more senior academics, yet, the respondents do adopt the excellence discourse in their rhetoric regarding early-career researchers.

Even though selecting for research quality seems to be taken for granted by the majority of Committee Members, this study also found resistance towards the discourse of excellence:

Well, I think, what drives me crazy is indeed the obsession with excellence. And for everybody; we all have to be excellent. Well, that is by definition impossible. Excellent means that you are far above average. So I am a little careful with using that word. (Natural Sciences 5)

This Committee Member makes a reference to the general 'obsession with excellence' in academia, revealing that the discourse has found its way into the system. Yet, the quote shows the difficulty inherent to the discourse of excellence: it is 'by definition impossible' for everybody to be excellent, which implies that the ambitions of the university and the department are infeasible.

Social sciences Committee Members in the Social Sciences Department argued too that research quality is the most important selection criterion for Assistant Professorships. In line with respondents in the Natural Sciences Department, they explained that selection criteria for Assistant Professor positions in the Social Sciences are pliant, because applicants for these positions are still junior.

Usually, an Assistant Professor is a very young person; someone who has just obtained a $\mathrm{PhD}$, or not yet obtained a $\mathrm{PhD}$. In this scenario, of course, you cannot expect very much. They just have a few publications and a little teaching experience. Well, of course they do not yet have administrative experience. Those are, of course, the three tasks. So, you're looking for someone you think is suitable to fulfil these three tasks, but, you cannot demand too much. (Social Sciences 2)

The quote shows that the experience and publications of applicants tend to be limited and, therefore, the Committee Member assesses the likelihood that a candidate can fulfil the required tasks in the future. This assessment of potential can be problematic, as potential in itself is a subjective criterion and its assessment is based on only limited past performance. This can create inequality, as potential is susceptible to bias and stereotypes. For instance, Van den Brink et al. (2016) have shown that men's potential is systematically evaluated higher than women's potential. 
Despite the omnipresence of the discourse of excellence at university and department level, some respondents argue that recruiting excellent Assistant Professors is hardly feasible. Therefore, they do not consent with macro- and meso-level criteria. One Committee Member stated that it is difficult to attract excellent candidates, because they have multiple offers from various institutions. Therefore, he argues, you have to win the 'competition' from 'other universities' in order to get the excellent candidate (Social Sciences 4). Another respondent argued that it is hard to attract excellent candidates because the department is not '(inter)nationally renowned' and, therefore, not appealing to excellent scholars (Social Sciences 2). She explained that excellent researchers opt for better-known universities in the field or wait for an offer. She confirmed the pressure of the university board on academic staff to strive for excellence and revealed the difficulties of this. Another Committee Member does not take selecting for excellence for granted either:

Personally, my strategy is that if I can choose between an A-candidate and a Bcandidate:-very excellent or good — and I know that with the good candidate, I would hire an outstanding team player, but the excellent candidate may be less adept at team work, I would pick the good candidate over the excellent one. The full team are required to be present for work every morning at nine, and have to work hard all day. I do not want to have to deal with team or individual staff issues the entire day. [...] Striving for excellence, also triggers certain processes, you know. The others, who are not excellent, might feel unappreciated. (Social Sciences 3)

This quote illustrates that the implicit norm of excellence does not encompass being a team player. Here, the Committee Member reproduces the dominant discourse of excellence, i.e. excellence equals individual research achievements. This makes excellence a narrow conception. Furthermore, the respondent explains how the presence of an excellent person in the team can create feelings of disadvantage among other staff and, therefore, endanger the ethos in the group. Thus, he resists the macro- and meso-level preoccupation with excellence. Here, a tension is found between what the university and department want and what an academic manager says they need for successful daily operation of their group.

\section{Discussion and conclusion}

This study aimed at providing a better understanding of how academic selection criteria for early-career researchers are constructed at the meso- and micro-level in the context of macro-discourses of internationalisation and excellence. Hitherto, early-career researchers were an understudied group in evaluation studies. This study shows how they need to be evaluated on their potential, rather than on track records of performance available for the assessment of senior researchers. This multi-level study contributes to the literature on academic staff evaluation (Lamont 2009; Musselin 2010; Nielsen 2016; Van den Brink and Benschop 2012) by showing that Committee Members do not operate in a vacuum and that their actions are inseparably linked to the meso- and macro-context. The present study uncovered the dynamic interaction between macro-discourses, formal organisational policies and the actual practice of Committee Members in staff evaluation. Furthermore, because of the multi-level analysis, this study could show the complexities and tensions inherent in the selection of early-career researchers and the inequalities that arise in the application of criteria. 
Three theoretical lessons can be drawn from the multi-level analysis contributing to the literature on academic staff evaluation. The first contribution is the identification of four inequalities that emerge in the application of criteria, where broad discourses materialise in specific criteria. The first inequality is related to (non-)valued international experience. The criterion of international work experience at university level is translated in the Natural Sciences Department into obtaining one or multiple postdoc positions abroad. The formal criterion implies that international experience in general is required, but some Committee Members narrowed this criterion by constructing only a small selection of countries and institutions as relevant and valuable international experience. The findings corroborate Altbach (2004), who found that mainly major international English-speaking research-oriented universities in the North are valued. This excludes candidates who acquired postdoc experience in countries or institutions that are non-valued, without standing a chance of being assessed on their quality as researchers and teachers.

The second inequality concerns language (dis)advantage, resulting from the tension between university's internationalisation policies and the application of those policies by Committee Members. The results show that mastering the academic lingua franca English is a formal criterion in policies, which is taken for granted by Committee Members. This study found that Committee Members in the Social Sciences Department make inferences about applicants' level of English, which can put applicants of certain nationalities at more of a disadvantage than others (Tietze and Dick 2009). In addition, applicants' level of Dutch is also at stake, as foreign Assistant Professors have to invest in learning Dutch, because of their duties in the teaching programme. This is in accordance with Nordic higher education, in which language policy prescribes adoption of 'parallel language use': the parallel use of several languages in the work of university staff (Airey et al. 2017, p. 568). Yet, it requires Tenure-Track Assistant Professors to strongly invest in learning the local language without the guarantee that they will get tenure. On the long-run, this creates an extensive period of precarity for early-career researchers. During recruitment and selection procedures, the language requirements can result in the exclusion of foreign applicants from the process, as some Committee Members perceive risks in hiring foreign applicants, anticipating communication problems and bad teaching evaluations.

Thirdly, this study finds inequalities regarding mobility opportunities that derive from a tension between the selection criterion of international work experience and a person's opportunity to acquire such experience. Policies and most Committee Members, particularly in the Natural Sciences Department, portray international mobility as necessary for an academic career. The requirement of international work experience demands mobility across country borders of early-career researchers (Richardson 2009), which assumes that researchers are able to travel. This means that the requirement of international work experience can be exclusionary to early-career researchers who face restrictions to their international mobility, for example due to physical, psychological, social or financial reasons (Richardson and Zikic 2007; Sang 2017).

The fourth inequality concerns unworkable excellence, stemming from a tension between the university's strive for excellence and Committee Members' infeasibility of assessing excellence. Some Committee Members do not believe it is either possible or desirable to hire (just) excellent staff members. This study shows that the criterion of excellence becomes problematic in application, as excellence is subjective, as well as difficult to evaluate for young scholars, since Committee Members can only assess their potential instead of proven qualities. Not only is excellence a socially constructed criterion that disadvantages women and 
privileges men researchers (O'Connor and O'Hagan 2015; Van den Brink and Benschop 2012), in the evaluation of potential, women are attributed lower potential than men (Van den Brink et al. 2016). Therefore, the application of excellence criteria can create inequalities related to gender and possibly other social categories too.

The second contribution of this article concerns disciplinary differences. The analysis has revealed the extent to which department policies and Committee Members are affected by macro-discourses. This study finds that in the Natural Sciences Department, formal selection criteria regarding internationalisation are most aligned with university-level policies, and Committee Members here consent explicitly to formal selection criteria reinforcing the discourse of internationalisation. In the Social Sciences Department, the macro-discourse of internationalisation and the university's internationalisation policy have not (yet) shaped formal selection criteria. Following Richardson (2009), the amount of international experience that is required depends on the discipline, with more experience expected in the Natural Sciences than the Social Sciences. The results show that most Committee Members in the Social Sciences tend to consent with departmental selection criteria and, therefore, do not apply international experience as a decisive criterion. This is in line with Clarke and Lunt (2014), who found that university-level assessment criteria for the evaluation of $\mathrm{PhD}$ research give guidance to examiners, but the discipline-specific context plays an important role in formulating criteria. When it comes to excellence, however, no disciplinary differences were found, as both the Natural Sciences and Social Sciences Department have adopted the discourse of excellence in their policies. This might confirm the pervasiveness of the macrodiscourse of excellence, yet, interestingly, this is the criterion in which most resistance was found by Committee Members in both departments.

The third and final contribution is the discovery of three different ways that Committee Members at the micro-level relate to articulations of the discourses of internationalisation and excellence. The majority of Committee Members in both departments consent to university policies and macro-discourses. They appropriate formal criteria, actively reproduce them as self-evident and sometimes even raise the bar. This is what Teelken (2012) refers to as formal instrumentality: 'the reliance on formal arrangements' 'without a critical perspective' (p. 278). However, it could be that the respondents have taken ownership of the macro-discourses and frame them as their personal preference rather than imposed on them by the organisation (Ashcraft 2005). Some Committee Members do problematise criteria but still comply with them, because they feel pressured by the organisation to do so. The type of compliance found is different from the symbolic compliance that Teelken (2012) found in her study, as respondents in this study did not seem to symbolically or cosmetically comply but actually adhere to imposed organisational criteria. However, compliance can also be a way to resist resistance (Kärreman and Alvesson 2009) or contain elements of resistance (Ashcraft 2005). A few Committee Members in both departments openly resist applying the criteria and do not take them for granted, recognising the disadvantages and narrowness of criteria of internationalisation and excellence. Committee Members specifically resisted the university requirement of hiring excellent staff, as they argue that it is either unfeasible or undesirable. Overall, this study finds that macro-discourses and university policies shape how a majority of Committee Members evaluate early-career researchers, but a smaller group questions and resists these criteria.

This article concludes that discourses of internationalisation and excellence that dominate the current neoliberal university create increasingly demanding criteria for Tenure-Track Assistant Professors. With only a few Committee Members critically questioning and resisting 
these criteria, their application by Committee Members may exclude talented early-career researchers. They limit the pool of 'acceptable' candidates to those who fit the narrow definition of the international mobile and excellent early-career researcher. As a final thought, this study has important practical implications for those who strive to change academic evaluation and reduce the inequalities in the application of criteria. Their interventions should not only target members of Selection Committees to change their evaluation practices but take into account how these practices at the micro-level are shaped by macro-discourses and organisational policies.

Acknowledgements We would like to thank Inge Bleijenbergh, Kathrin Zippel, and three anonymous reviewers for their helpful comments on earlier drafts of the manuscript.

Funding information The research leading to these results has received funding from the European Union's Seventh Framework Programme (FP7/2007-2013) under grant agreement no. 611737.

Open Access This article is distributed under the terms of the Creative Commons Attribution 4.0 International License (http://creativecommons.org/licenses/by/4.0/), which permits unrestricted use, distribution, and reproduction in any medium, provided you give appropriate credit to the original author(s) and the source, provide a link to the Creative Commons license, and indicate if changes were made.

\section{References}

Airey, J., Lauridsen, K. M., Räsänen, A., Salö, L., \& Schwach, V. (2017). The expansion of English-medium instruction in the Nordic countries: can top-down university language policies encourage bottom-up disciplinary literacy goals? Higher Education, https://doi.org/10.1007/s10734-015-9950-2.

Altbach, P. G. (2004). Globalisation and the university: myths and realities in an unequal world. Tertiary Education and Management, https://doi.org/10.1080/13583883.2004.9967114.

Anderson, G. (2008). Mapping academic resistance in the managerial university. Organization, https://doi. org/10.1177/1350508407086583.

Anninos, L. N. (2014). Research performance evaluation: some critical thoughts on standard bibliometric indicators. Studies in Higher Education, https://doi.org/10.1080/03075079.2013.801429.

Ashcraft, K. L. (2005). Resistance through consent? Occupational identity, organizational form, and the maintenance of masculinity among commercial airline pilots. Management Communication Quarterly, https://doi.org/10.1177/0893318905276560.

Basu, A. (2006). Using ISI's 'highly cited researchers' to obtain a country level indicator of citation excellence. Scientometrics, https://doi.org/10.1007/s11192-006-0117-x.

Benders, J., \& Van Veen, K. (2001). What's in a fashion? Interpretative viability and management fashions. Organization, https://doi.org/10.1177/135050840181003.

Bessudnov, A., Guardiancich, I., \& Marimon, R. (2015). A statistical evaluation of the effects of a structured postdoctoral programme. Studies in Higher Education, https://doi.org/10.1080/03075079.2014.899340.

Bryman, A. (1989). Research methods and organization studies. New York: Routledge.

Bryman, A., \& Bell, E. (2007). Business research methods (Second ed.). New York: Oxford University Press Inc..

Burawoy, M. (1979). Manufacturing consent: changes in the labor process under monopoly capitalism: University of Chicago Press.

Butler, N., \& Spoelstra, S. (2014). The regime of excellence and the erosion of ethos in critical management studies. British Journal of Management, https://doi.org/10.1111/1467-8551.12053.

Chism, N. V. N. (2006). Teaching awards: What do they award? The Journal of Higher Education, https://doi. org/10.1080/00221546.2006.11772308.

Clarke, G., \& Lunt, I. (2014). The concept of 'originality' in the Ph.D.: how is it interpreted by examiners? Assessment \& Evaluation in Higher Education, https://doi.org/10.1080/02602938.2013.870970.

Davies, B., \& Davies, B. J. (2010). Talent management in academies. International Journal of Educational Management, https://doi.org/10.1108/09513541011055983. 
De Boer, H. F., Enders, J., \& Leisyte, L. (2007). Public sector reform in Dutch higher education: The organizational transformation of the university. Public Administration. https://doi.org/10.1111/j.14679299.2007.00632.x.

De Goede, M., Belder, R., \& De Jonge, J. (2013). Academic careers in the Netherlands. The Hague: Rathenau Institute.

Enders, J., \& Teichler, U. (1997). A victim of their own success? Employment and working conditions of academic staff in comparative perspective. Higher Education. https://doi.org/10.1023 /A:1003023923056.

Fabricius, A. H., Mortensen, J., \& Haberland, H. (2017). The lure of internationalization: paradoxical discourses of transnational student mobility, linguistic diversity and cross-cultural exchange. Higher Education. https://doi.org/10.1007/s10734-015-9978-3.

Field, L. (2015). Appraising academic appraisal in the new public management university. Journal of Higher Education Policy and Management. https://doi.org/10.1080/1360080X.2014.991534.

Gill, R. (2009). Breaking the silence: the hidden injuries of the neoliberal university. In R. Flood \& R. Gill (Eds.), Secrecy and silence in the research process: Feminist reflections. London: Routledge.

Jepsen, D. M., Sun, J. J.-M., Budhwar, P. S., Klehe, U.-C., Krausert, A., Raghuram, S., et al. (2014). International academic careers: personal reflections. The International Journal of Human Resource Management, https://doi.org/10.1080/09585192.2013.870307.

Kärreman, D., \& Alvesson, M. (2009). Resisting resistance: counter-resistance, consent and compliance in a consultancy firm. Human Relations, https://doi.org/10.1177/0018726709334880.

Knight, J. (1994). Internationalization: Elements and checkpoints. Canadian Bureau for International Education Retrieved October 18, 2017 from http:/files.eric.ed.gov/fulltext/ED549823.pdf.

Lamont, M. (2009). How professors think: inside the curious world of academic judgment: Harvard University Press.

Leisyte, L., \& Rose, A.-L. (2016). The challenges of attracting and retaining academic talent: central and eastern European perspectives. Journal of European Higher Education Area, 4, 61-82.

Lieblich, A., Tuval-Mashiach, R., \& Zilber, T. (1998). Narrative research: reading, analysis and interpretation. SAGE Publications Ltd.

Lovitts, B. E. (2007). Making the implicit explicit: creating performance expectations for the dissertation. Virginia: Stylus Publishing.

Lund, R. W. (2015). Doing the ideal academic: gender, excellence and changing Academia.

Maesse, J. (2017). The elitism dispositif: hierarchization, discourses of excellence and organizational change in European economics. Higher Education, https://doi.org/10.1007/s10734-016-0019-7.

Meriläinen, S., Tienari, J., Thomas, R., \& Davies, A. (2008). Hegemonic academic practices: Experiences of publishing from the periphery. Organization, https://doi.org/10.1177/1350508408091008.

Musselin, C. (2005). European academic labor markets in transition. Higher Education, https://doi.org/10.1007 /s10734-004-2918-2.

Musselin, C. (2010). The market for academics: Routledge.

Nielsen, M. W. (2016). Limits to meritocracy? Gender in academic recruitment and promotion processes. Science and Public Policy, https://doi.org/10.1093/scipol/scv052.

O'Connor, P., \& O'Hagan, C. (2015). Excellence in university academic staff evaluation: a problematic reality? Studies in Higher Education, https://doi.org/10.1080/03075079.2014.1000292.

Olssen, M., \& Peters, M. A. (2005). Neoliberalism, higher education and the knowledge economy: from the free market to knowledge capitalism. Journal of Education Policy, https://doi.org/10.1080/02680930500108718.

Özbilgin, M. F. (2009). From journal rankings to making sense of the world. Academy of Management Learning \& Education, https://doi.org/10.5465/AMLE.2009.37012185.

Panayiotou, A., Putnam, L. L., \& Kassinis, G. (2017). Generating tensions: a multilevel, process analysis of organizational change. Strategic Organization, 1-30. https://doi.org/10.1177/1476127017734446.

Porter, R. (2005). What do grant reviewers really want, anyway? Journal of Research Administration, 36(2), 513,13 .

Pringle, J. K., \& Ryan, I. (2015). Understanding context in diversity management: a multi-level analysis. Equality, Diversity and Inclusion: An International Journal, https:/doi.org/10.1108/EDI-05-2015-0031.

Ramirez, F. O., \& Tiplic, D. (2014). In pursuit of excellence? Discursive patterns in European higher education research. Higher Education, https://doi.org/10.1007/s10734-013-9681-1.

Richardson, J. (2009). Geographic flexibility in academia: a cautionary note. British Journal of Management, https://doi.org/10.1111/j.1467-8551.2008.00641.x.

Richardson, J., \& Zikic, J. (2007). The darker side of an international academic career. Career Development International, https://doi.org/10.1108/13620430710733640.

Sang, K. (2017). Disability and academic careers. Retrieved October 18, 2017 from https://migrantacademics. files.wordpress.com/2017/05/disability-sang-may-2017.pdf 
Schartner, A., \& Cho, Y. (2017). 'Empty signifiers' and 'dreamy ideals': perceptions of the 'international university' among higher education students and staff at a British university. Higher Education. https://doi.org/10.1007/s10734-016-0057-1.

Schinkel, W. (2017). Laten we het over institutioneel seksism op de universiteit hebben. Retrieved October 12, 2017 from https://versbeton.nl/2017/10/laten-we-het-over-institutioneel-seksisme-op-de-universiteithebben/.

Silverman, D. (2011). Interpreting qualitative data: a guide to the principles of qualitative research (Vol. 4). SAGE Publications Ltd.

Slaughter, S., \& Leslie, L. L. (1997). Academic capitalism: politics, policies, and the entrepreneurial university: Johns Hopkins University Press.

Teelken, C. (2012). Compliance or pragmatism: how do academics deal with managerialism in higher education? A comparative study in three countries. Studies in Higher Education, https://doi.org/10.1080 /03075079.2010.511171.

Thunnissen, M., Boselie, P., \& Fruytier, B. (2013). Talent management and the relevance of context: Towards a pluralistic approach. Human Resource Management Review, https://doi.org/10.1016/j.hrmr.2013.05.004.

Tietze, S., \& Dick, P. (2009). Hegemonic practices and knowledge production in the management academy: an English language perspective. Scandinavian Journal of Management, https://doi.org/10.1016/j. scaman.2008.11.010.

Van Arensbergen, P., Van der Weijden, I., \& Van den Besselaar, P. (2014). Different views on scholarly talent: what are the talents we are looking for in science? Research Evaluation, https://doi.org/10.1093 /reseval/rvu015.

Van den Brink, M., \& Benschop, Y. (2012). Gender practices in the construction of academic excellence: sheep with five legs. Organization, https://oi.org/10.1177/1350508411414293.

Van den Brink, M., Fruytier, B., \& Thunnissen, M. (2013). Talent management in academia: performance systems and HRM policies. Human Resource Management Journal, https://doi.org/10.1111/j.17488583.2012.00196.x.

Van den Brink, M., Holgersson, C., Linghag, S., \& Deé, S. (2016). Inflating and down playing strengths and weaknesses - practicing gender in the evaluation of potential managers and partners. Scandinavian Journal of Management, https://doi.org/10.1016/j.scaman.2015.11.001.

Washburn, J. (2005). University, Inc.: The corporate corruption of American higher education. New York: Basic Books.

Werner, R. (2015). The focus on bibliometrics makes papers less useful. Nature, https://doi.org/10.1038/517245a. 